\title{
Porous granules formation from oil crops by extrusion process: a theoretical perspective
}

\author{
Zaur A. Meretukov ${ }^{1}$, Evgeny P. Koshevoy ${ }^{2}$, Ivan A. Shorstkii ${ }^{2, *}{ }^{*}$ and Charles Odilichukwu R. Okpala ${ }^{3}$ \\ ${ }^{1}$ Maykop State Technological University, Universitetskaya str. 191, Maykop, Russia \\ ${ }^{2}$ Kuban State Technological University, Moscowskaya str. 2, Krasnodar, Russia \\ ${ }^{3}$ Faculty of Biotechnology and Food Sciences, Wrocław University of Environmental and Life Sciences, Wrocław, Poland
}

Received 12 January 2021 - Accepted 7 September 2021

\begin{abstract}
The introduction of extruders, in particular how it works and its principles, must be started from the definition of the extrusion process, the description of its development and types, as well as its functions and advantages. In order to understand the process of extrusion technology, it is necessary to go into detailed descriptions and discussions together with theoretical insights of the subject. In the present article, we discuss a theoretical perspective of production of porous granules from oil crops by extrusion technology. Let's divide this theoretical perspective into three steps. At first, we study the modeling of statics of oil crop mix compressibility together with carbon dioxide. At second, we study the heat exchange and phase transformation during the stroke of oil crop extruder filled with $\mathrm{CO}_{2}$. At third, we observe the deformation of the oil crops during the extrusion process. There is a probability that extrusion process of oil crop mix with the hard phase of carbon dioxide provides technological way that does not overheat the cellular structure. Potentially, the equation of Van der Waals is able to describe the change in volume of oil crops, which may be related with range of factors associated with volume expansion, calculated by equations as the expansion of granule material takes place at the outlet of extruder matrix. The extrusion processing of a mix of oil crops and carbon dioxide in hard phase at initial stage may likely occur as temperature declines. The resulting values show good compliance of theoretical results to experimental data on the example of coriander seeds.
\end{abstract}

Keywords: extrusion / oil crops / carbon dioxide / phase transition / pressure

\begin{abstract}
Résumé - Formation de granules poreux à partir de graines oléagineuses par extrusion: une perspective théorique. Une présentation des extrudeurs, en particulier de leur fonctionnement et de leurs principes, doit commencer par la définition du procédé d'extrusion, la description de son développement et de ses types, ainsi que de ses fonctions et autres avantages. Afin de comprendre le procédé d'extrusion, il est nécessaire d'entrer dans des descriptions et des discussions détaillées ainsi que dans des aperçus théoriques du sujet. Dans le présent article, nous abordons, sous un angle théorique, la production de granules poreux à partir de graines oléagineuses par extrusion. Cette perspective théorique a été divisée en trois étapes. Dans un premier temps, nous étudions la modélisation de la statique de la compressibilité d'un mélange d'une graine oléagineuse avec du dioxyde de carbone. Dans un deuxième temps, nous étudions les échanges de chaleur et la transformation des phases lors du traitement d'une graine oléagineuse dans un extrudeur rempli de $\mathrm{CO}_{2}$. Enfin, nous observons la déformation de la graine oléagineuse au cours du procédé d'extrusion. Il est probable que le processus d'extrusion d'une graine oléagineuse mélangée à la phase critique du dioxyde de carbone offre un moyen technologique permettant de ne pas surchauffer la structure cellulaire. Potentiellement, l'équation de Van der Waals est capable de décrire le changement de volume de la graine oléagineuse, qui peut être lié à une série de facteurs associés à l'expansion du volume, calculée par des équations qui rendent donc compte de l'expansion du matériau granulaire en sortie d'extrudeur. L'extrusion d'un mélange d'une graine oléagineuse et de dioxyde de carbone en phase critique au stade initial peut vraisemblablement se produire lorsque la température diminue. Les valeurs obtenues montrent une bonne conformité des résultats théoriques aux données expérimentales obtenues, par exemple sur des graines de coriandre.
\end{abstract}

Mots clés : extrusion / graines oléagineuses / dioxyde de carbone / transition de phase / pression

*Correspondence: i-shorstky@mail.ru 


\section{Highlights}

Oil crops extrusion with carbon dioxide as a preliminary step for further extraction considered as controllable and perspective technology.

Heat transfer and deformation theory during material extrusion process is considered.

Obtained theoretical results and equations can be used for extrusion process modeling and simulation.

\section{Introduction}

The introduction of extruders, in particular the way of its work and guiding principles, must be started by the definition of the extrusion processing, its development and types. This introduction shall be presented together with the functions and advantages (Riaz, 2000). Further, the extrusion process, as a highly sophisticated technology, greatly depends on a continuous operation. So, it confers the certain responsibility on the extruders operators (Bouvier and Campanella, 2014). Different types of extruders, such as single-screw extruders and twin-screw extruders, have been widely studied for their operation on different oil crops (Isobe et al., 1992; Vandenbossche et al., 2019). However, single-screw presses are most commonly used in industrial practices, as they are much less expensive regarding to the investment costs (Uitterhaegen and Evon, 2017). Further analysis will be run for single-screw extruders. Types of extrusion range from compression/transport of certain components, production of (bio)polymeric materials, defibering and chemical impregnation of fibrous materials, fractionation of solid-liquid media, melting of polymers, mixing of viscous media, shaping of product and texturing of product to reactive extrusion (Bouvier and Campanella, 2014; Vandenbossche et al., 2019). The extruded material can undergo further physical changes due to the product expansion. In wide extent, the obtained porosity of a product is a key factor that influences the product characteristics, which represents the effects of the extrusion (cooking) process (Chiruvella et al., 1996). From the practical point of view, the preparation of raw material for the change of its internal structure and pore volume increasing plays one of the most important roles for extraction of oil.

Extrusion can bring various products under diverse conditions and at a predetermined rate(s) by forcing of the processed material to flow through a shaped hole in general (Alam et al., 2016). This process takes place among the key aspects of extrusion that causes multi-functional, multi-step, thermal/mechanical and chemical changes (adding of chemicals, adding of extracting solvents, procedure of reactive extrusion, etc.), which has given several ways for food processing (Singh et al., 2007). Additionally, there are three major factors that drive the development of extrusion process technology for production of food, paper and in plastic milling industry, and at smaller scale those factors are used for extracting biomolecules especially with "green" (environmentally friendly) solvents. That major factors include: (a) the environmentally friendly essence of the process, (b) the rate of productivity (continuous, flexible, sophisticated processing), and (c) the functionality and innovation it brings to the obtained product (Bouvier and Campanella, 2014). In general, the extrusion machinery (also called extruders) consists of a gear reducer and motor drive system. Further, the design (both the gear reducer and motor drive system) determines the torque and speed range of productivity that the extrusion machinery can cover. Additionally, the extruder's performance is fundamentally defined by its torque and speed range, particularly in terms of process productivity, as well as product conversion (Maskan and Altan, 2012; Bouvier and Campanella, 2014).

Notwithstanding the above, the extrusion studies focus on either two or three primary extrusion variables. Nonetheless, other factors that should be taken into consideration can include temperature of the extrusion barrel, press mold geometry, extruder type, feed rate and its related components (for example, composition, moisture content, particle size), as well as screw configuration/speed of rotation, which factors influence the product quality. Another aspect of extrusion studies includes the composition of ingredients, which can affect the final product quality through the extruder performance or accompanying variables (for instance, motor torque, achieved pressure, product temperature and stroke) (Sriti et al., 2011). Considering all the above parameters, it is necessary to study them permanently for better understanding of extrusion processing technology, and this, according to Bouvier and Campanella (2014) would require detailed descriptions and discussions as well as analysis of this particular subject area. Additionally to above-listed parameters, the model of extrusion processes involves not only multiple processes of input and output, but also process parameters and system parameters, as well as the properties of product. Considering the large number of variables within the process of extrusion, as well as non-linear relations that prevail among them, several approximations have to be made, which can imply some limitations to the outcomes/results of mathematical models (Shihani et al., 2006).

In this short research, we present a theoretical perspective of production of porous granules from oil crops by extrusion technology assisted by carbon dioxide in hard phase. Carbon dioxide aided extrusion has some advantages in comparison with traditional pretreatment methods: (1) cell disintegration during carbon dioxide phase transition, (2) low process temperatures without overheating and "explosion" of granules in the extruder outlet.

Considering that extruders crush the material intensively, the cell structure is also ruptured, and through this rupture, the pressing screw facilitates production of oil. Additionally, the type and design of extruder screws and its pressing efficiency determine how variable the extrusion process can be, which is underscored in evaluation of the thermomechanical pressing of seeds of various oil crops, such as sunflower, rapeseed, and coriander seeds (Uitterhaegen and Evon, 2017).

We will discuss this theoretical opinion in three steps. At first, we study the modeling of compressibility statics of oil crops mixed with carbon dioxide. At second, we study heat exchange and phase transformation at stroke movement of extruder filled with oil crops and $\mathrm{CO}_{2}$. At third, we consider the deformation of oil crops during the extrusion process. 


\section{Theoretical perspectives}

\subsection{Modeling of compressibility statics in oil crops mixed with carbon dioxide}

Computer modeling and simulation of compacted seeds layer in the extraction capacity can help develop and optimize the process of supercritical (SC) extraction of carbon dioxide $\left(\mathrm{CO}_{2}\right)$ from solid substrates (del Valle, 2015). These simulations, in their turn, require mathematical models to describe mass transfer within solid particles from stationary particles to moving $\mathrm{SC}-\mathrm{CO}_{2}$ stream, and within this moving stream, as it was described by del Valle and de La Fuente (2006) for specific case of oil extraction from rape, canola, grape seeds and related biological substrates. Models must be of a predictive type, especially in situations where experimental data collection may be impeded or nearly impossible, such as simulating countercurrent contact in a multi-vessel industrial SC- $\mathrm{CO}_{2}$ extraction facility. The cut-Core model (South Carolina) was successfully applied on wide range of oilseeds exposed to intense shear forces during pre-pressing and/or peeling (del Valle and de la Fuente, 2006), and this model was later preemptively applied to simulate pseudocountercurrent contact between pre-pressed oilseeds and $\mathrm{SC}-\mathrm{CO}_{2}$ in industrial multivessel plants (Núñez et al., 2011). This computational model is used to reduce the costs. It is influenced by the substrate particle size, conditions, process and quantity, size and shape of extrusion vessels (Núñez et al., 2017). Unfortunately, the SC model appears computationally intensive in the sense that it deals with variations in the oil content in radial position within the substrate particles. An alternative that takes into consideration, only the average residual oil content uses hypothesis of linear driving force (LDF) to quantify the transfer of oil from the substrate to $\mathrm{CO}_{2}$, but this requires a constant equilibrium distribution of oil between the two phases. However, it has been experimentally proven that the separation of oil between a sample of pre-compressed oilseed and $\mathrm{CO}_{2}$ is nonlinear due to limitations imposed by solubility of oil in $\mathrm{SC}^{-\mathrm{CO}_{2}}$ under process conditions (Urrego et al., 2015).

Production of porous granules with an extruder is an efficient way of preparation of oil crops for oil extraction (Toledo et al., 2020). It is possible to run this process due to the "explosive" character of granules expansion at the outlet of the extruder, which is at the intensive phase transition of a liquid component within the material (Jedinger et al., 2015). Oil crops always incorporate a liquid component-moisture. The quantity of moisture can be various, but its basic quantity is quite defined in general, and at the moment of seed compression, this moisture is not squeezed out. Air and moisture as steam phase, fill inter-partial space, which is present at initial state of material, but they leave off material at initial stages of compression, thus making its further presence negligible (Bisharat et al., 2013). In order to run the seeds, expansion ("explosion") of extruded material due to steam on a material at sudden discharge of pressure especially on the outlet, and from an outlet hole of a extruder matrix, it is necessary to provide a high level of temperature that can essentially worsen quality of extruded materials (Song et al., 2017).

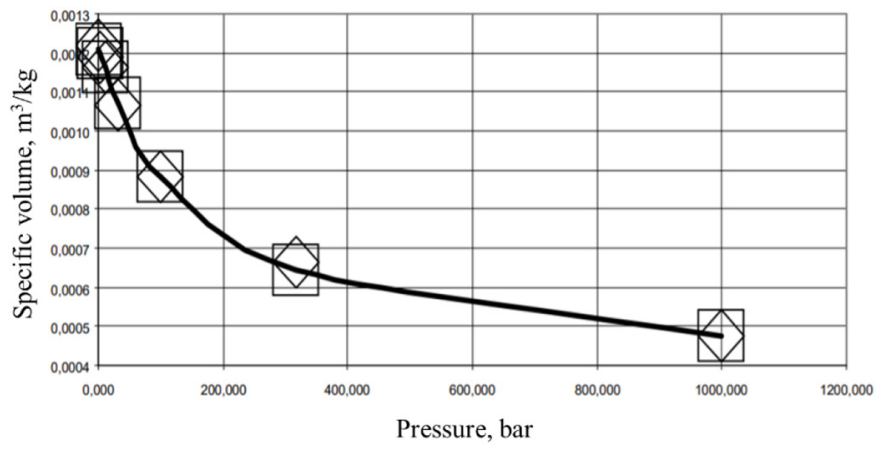

Fig. 1. Dependence of specific volume of coriander seeds on pressure: $\diamond$ : experimental sample values; $\square$ : model values.

Generally, it is possible to present the liquid as component that differs moisture and moisture influence on properties, for example, carbon dioxide in structure of a processed material can be introduced into raw material in form of dry ice in order to mix up under atmospheric pressure and further moving ahead into the extruder channel under an increasing pressure to turn consistently to a liquid and steam phase (De Melo et al., 2017). Carbon dioxide is intentionally introduced into the crop for achievement of the best "explosion" by preparation of a material for extrusion extraction. In connection with this common approach further, we use a designation for specially added component $-\mathrm{CO}_{2}$ (carbon dioxide), and the moisture will be neglected in computations because in this case its influence is not essential (Tong and Hai, 2017).

As the material moves along within the extruder's screw channel, there is an increase in pressure in a prematrix zone (Said et al., 2016). In the situation where there are no devices for heat removal, the material increases the temperature. Thus, because of increase in pressure and temperature on a processed material, there is phase transition of $\mathrm{CO}_{2}$ from a solid state in interpartial space into a liquid condition. In connection with it, equilibrium is achieved in steam condition according to the diagram of a phase condition (Bernhard, 1974). At the same time, in process of approaching of seeds mix to matrix within a steam phase, the interpartial space reduces.

At the first stage, the statics of compressibility of oil crops mixtures with carbon dioxide was computed using mathematical modelling. Carbon dioxide is specially introduced by preparation of material for extraction by extrusion to obtain effect of "explosion" at a low temperature in comparison with steam. The modified equation of Van der Waals condition is applied for oil crops according to solid-phase behavior description (Chiruvella et al., 1996):

$$
(P+\pi)\left(v_{M}-\omega\right)=R^{\prime} T,
$$

where $\mathrm{P}$ is the pressure, bar; $v_{\mathrm{M}}$ is the specific volume of material, $\mathrm{m}^{3} / \mathrm{kg} ; \pi, \omega$ and $\mathrm{R}^{\prime}$ are the empirical constants.

To calculate the phase transformations of carbon dioxide, a smooth functional relationship in the form of cubic spline approximation of Van der Waals' equation was used. The obtained data on factors of compressibility allowed calculating density at a variation of pressure and temperature in a practically significant range, and also structure of the exploded $\operatorname{mix}\left(\mathrm{CO}_{2}\right.$ up to 10 mass, \%). 


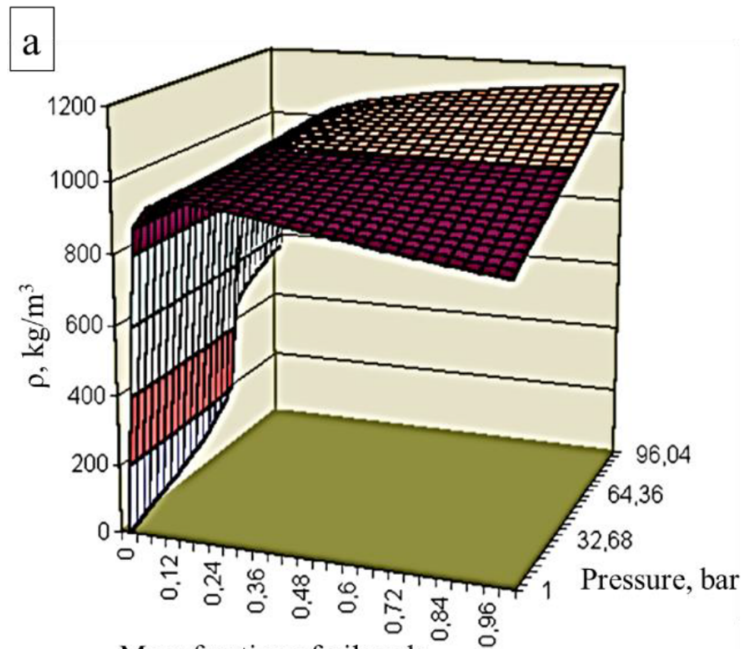

Mass fraction of oilseeds

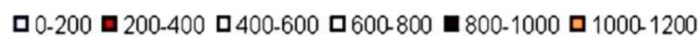

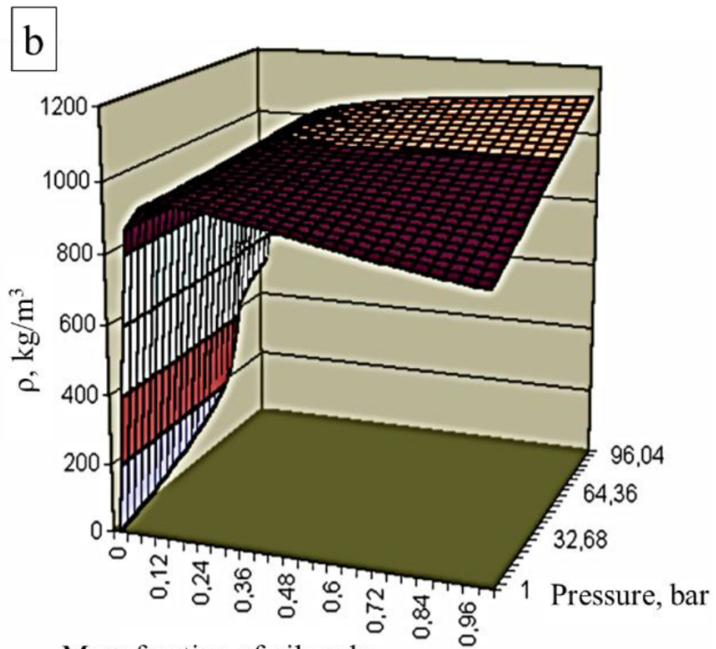

Mass fraction of oilseeds

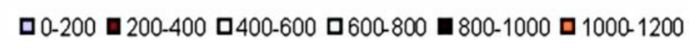

Fig. 2. Comparison of oil crop mix density with mass fraction of oilseeds (complement to 1 being the solid $\mathrm{CO}_{2}$ ) and pressure in various temperatures: $298 \mathrm{~K}$ (a) and $308 \mathrm{~K}$ (b).

To validate applicability of equation (1) for behavior of oil crops with solid $\mathrm{CO}_{2}$ mixture, let's transform equation (1) to the following form:

$$
v=\frac{R^{\prime} T}{P+\pi}+\omega
$$

An experimental data of coriander seeds compression parameters (Fig. 1), obtained in our previous paper (Meretukov and Koshevoy, 2014), was used for case study of compressibility of oil crops mixed with solid $\mathrm{CO}_{2}$.

During processing, the following values of the equation coefficients (2) were obtained: $\omega=0.000357 ; \mathrm{R}^{\prime} \mathrm{T}=0.138$ and $p=161.15$. The dependencies shown in Figures $2 a$ and $2 b$ are the same, and the temperature does not provide a significant effect within the specified range. Low density is peculiar for carbon dioxide, and it sharply increases up even with proportion of seeds in the mixture to $0.05-0.06$.

The obtained model allowed estimation of the factor of volumetric expansion from the pressed condition:

$$
\alpha_{P V}=\frac{1}{\rho_{c}}\left(\frac{\partial \rho_{c}}{\partial P}\right)_{T}=-\frac{1}{v_{c}}\left(\frac{\partial v_{c}}{\partial P}\right)_{T} .
$$

Approximation of calculated density of cubic splines and derivative, considering the calculations in accordance with equation (3), allowed drawing up the dependences of volume expansion coefficient on mass fraction of oilseeds (complement to 1 being the solid $\mathrm{CO}_{2}$ ) and pressure in case of two temperatures of $298 \mathrm{~K}$ and $308 \mathrm{~K}$. The results are shown below in Figures $3 \mathrm{a}$ and $3 \mathrm{~b}$. For both temperatures, the curvature of dependences and values of volume expansion coefficients are almost the same, as can be seen in Figures $3 \mathrm{a}$ and $3 \mathrm{~b}$.

Volume expansion coefficients increase along with the increase of coriander mass fraction in the seeds mixture. The results of calculation of volumetric expansion (factor $\alpha_{p v}$ ) for temperature range of $298 \mathrm{~K}-308 \mathrm{~K}$ have shown that increase of $\alpha_{p v}$ depends on growth of mass ratio of oil crop in whole mixture. Increase of pressure factor occurs along with decrease of volumetric expansion factors. According to the research (Meretukov and Koshevoy, 2014), the compression value of extruded mixes can be calculated as follows:

$$
A_{\text {compr }}=v_{0}\left(\frac{1}{\alpha_{p v}}\left(\exp \left(-\alpha_{p v} P+1\right)+P \exp \left(-\alpha_{p v} P\right)\right)\right) .
$$

The simulation output resulted to numerical values of main parameters in deformation process of the processed plant material mixed with solid $\mathrm{CO}_{2}$. It can be noted that in case of mass of carbon dioxide within the range of $3-5 \%$ in the mixture, it is possible to obtain the properties necessary to conduct the process of extrusion of the mixture with its subsequent expansion.

\subsection{Heat transfer and phase transformation during movement of oil crops and $\mathrm{CO}_{2}$ in extruder}

Extrusion process of oil crops mixed with solid $\mathrm{CO}_{2}$ is offered for production of "exploded" oil crops grains necessary for $\mathrm{CO}_{2}$-extraction. The advantage of this approach, particularly in preparation stage, is its producibility at a rather low temperature, and filling of porous space with carbon dioxide. During the extrusion process, particularly at the movement of a mix of oil crops within the solid $\mathrm{CO}_{2}$ in the channel, the pressure rises up and the solid $\mathrm{CO}_{2}$ triggers explosion due of heat obtained from friction. This condition of this phase (liquid or solid) depends on pressure and temperature, which will be considered. However, at the extruder matrix outlet, the carbon dioxide expands and "explodes" porous structure of oil crops.

To estimate the process at extrusion of crops mixed with solid $\mathrm{CO}_{2}$, it is necessary to consider the equations of movement and energy which can be used as model of process. As a result of numerical modelling, the key parameters of deformation of oil crops mixed with carbon dioxide were obtained. In order to estimate the process at extrusion of grain 


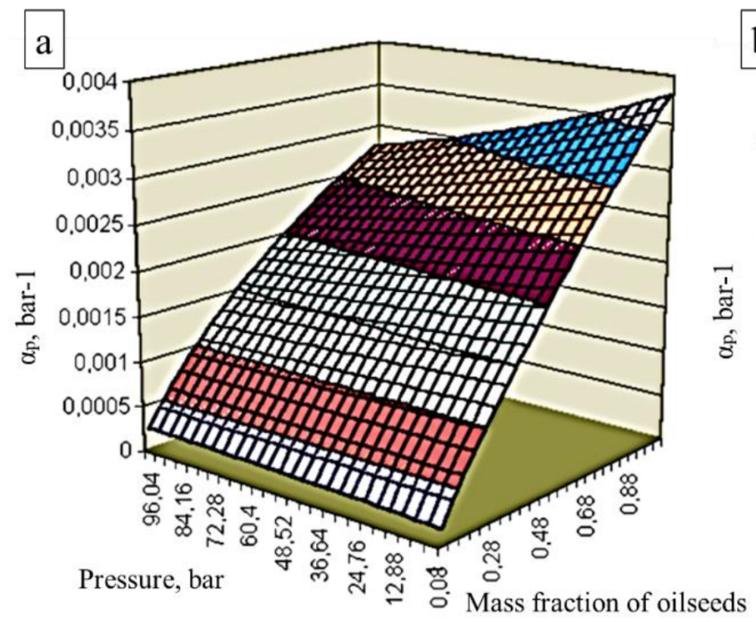

口0-0,0005 घ0,0005-0,001 ם0,001-0,0015 व0,0015-0,002

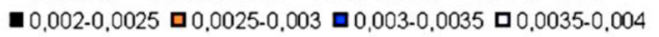

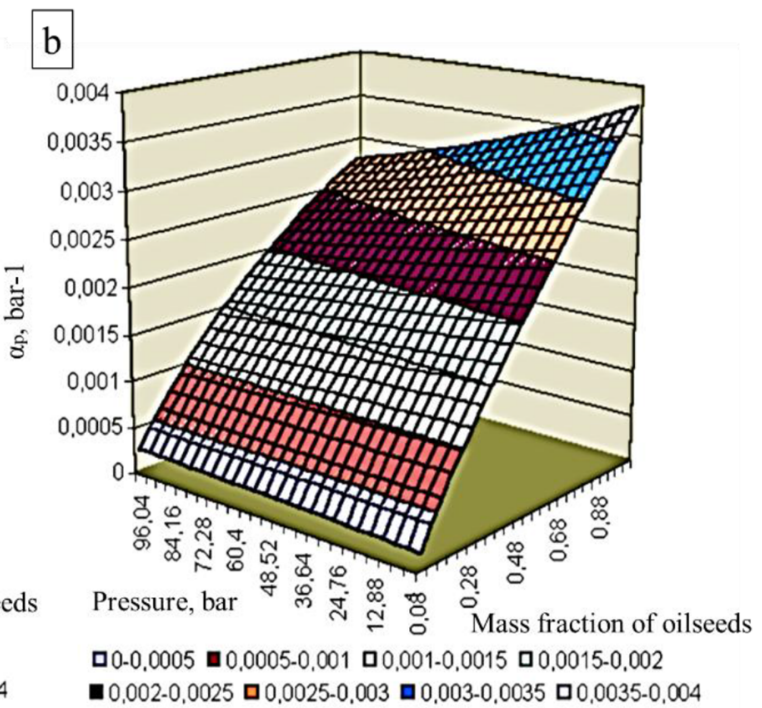

Fig. 3. Volume expansion coefficient versus mass fraction of oilseeds (complement to 1: solid $\mathrm{CO}_{2}$ ) and pressure for different temperatures: $298 \mathrm{~K}$ (a) and $308 \mathrm{~K}$ (b).

mixed with solid $\mathrm{CO}_{2}$, the equations of movement and energy were considered which can be used as model of process. The equation of energy from Chiruvella et al. (1996) looks as follows:

$$
\begin{gathered}
\frac{\partial}{\partial z}\left(\rho \cdot C_{p} \cdot w(y, z) \cdot T(y, z)\right)=\left(\frac{H_{0}}{H_{z}}\right)^{2} \frac{\partial}{\partial y}\left(\lambda_{M} \frac{\partial T(y, z)}{\partial y}\right) \\
+\left(\frac{H_{0}}{H_{z}}\right)^{2} \mu_{M} \cdot\left(\frac{\partial w(y, z)}{\partial y}\right)^{2}-\frac{S}{L_{e}}
\end{gathered}
$$

where $\rho$ is the density of a material, $\mathrm{kg} / \mathrm{m}^{3} ; \mathrm{C}_{\mathrm{p}}$ is the specific thermal capacity of extruded material, $\mathrm{J} / \mathrm{K} \cdot \mathrm{kg} ; w=w(y, z)$ is the distribution of speed of extruded material in relation to coordinates $\mathrm{y}$ and $\mathrm{z}, \mathrm{m} / \mathrm{s} ; T=T(y, z)$ is the distribution of temperature of extruded material on coordinates $\mathrm{y}$ and $\mathrm{z}, \mathrm{K} ; \mathrm{1}_{\mathrm{M}}$ is the heat conductivity of extruded material, $\mathrm{Wt} / \mathrm{m} \cdot \mathrm{K} ; \mathrm{S}$ is the drain of heat at phase transition of carbon dioxide, $\mathrm{Wt} / \mathrm{m}^{2}$; $H_{z}=\left(H_{0}-a z\right)$ is the variable depth of the channel, $\mathrm{m} ; H_{0}$ is the initial depth of a coil, $m ; \mu_{M}$ is the viscosity of extruded material (non Newtonian liquid), $\mathrm{Pa} \cdot \mathrm{s} ; L_{e}$ is the length of the channel, $\mathrm{m}$.

Distribution of material speed in a channel from Chiruvella et al. (1996) is as follows:

$$
\begin{aligned}
w(z, y) & =\frac{1}{2 \mu_{M}}\left[\frac{G}{H_{z}^{2}}-\frac{Q}{B \cdot H_{z}^{3}}\right] y^{2} \\
& -\frac{\left[A \cdot H_{z} \cdot y^{2}-Q y^{2}-2 \cdot H_{z}^{3} B \mu \cdot V\right]}{H_{z}^{3} \cdot B \mu_{M}} .
\end{aligned}
$$

It is obtained from the equation of extruder volumetric productivity:

$$
Q=A \cdot H_{z}-B \cdot H_{z}^{3}(d P / d z)
$$

where $A=\pi \cdot D_{e} \cdot W_{b} \cdot N \cdot \cos \theta \cdot\left(\frac{f_{d}}{2}\right) ; \quad B=\left(W_{b} \cdot f_{p s} \cdot f_{p d}\right) /(12 \cdot n$. $\left.\mu_{c}\right) ; W_{\mathrm{B}}=S_{c} \cdot \operatorname{cosq_{\mathrm {B}}}$ is the width of a coil, $\mathrm{m} ; S c$ is the step, $\mathrm{m} ; \mathrm{q}=\operatorname{arctg}\left[\mathrm{S} /\left(\mathrm{pD}_{\mathrm{e}}\right)\right]$ is the angle of inclination of coil thread, radian; $f_{d}=1-\left(0,487 n^{2}-0,948 n+0,972\right) H_{z} / W$ is the factor of form of forced stream; $f_{p s}=1-\left(0,949 n^{2}-1,87 n+1\right.$, 59) $H_{z} / W$ is the factor of form for a countercurrent caused by resistance of the target device; $f_{p d}=0.98$ is the correcting factor for average viscosity in stream (for the area of interest); $D_{e}$ is the diameter of the case of extruder, $\mathrm{m} ; \mathrm{N}$ is the rotation speed of extruder screw, $\mathrm{s}^{-1} ; \mathrm{n}$ is the parameter of the sedate law in the equation of current of extruded material (non-Newtonian liquid: for oil crops $n=0.13$ ).

Having considered terms of the equation of energy in view of numerical values of material properties, the equation can be presented in general view as follows:

$$
\frac{\partial}{\partial z} T(y, z)=m_{1} \cdot \frac{\partial^{2}}{\partial y^{2}} T(y, z)-m_{2} \cdot T(y, z)-m_{3} .
$$

With boundary conditions of the first sort:

$\mathrm{T}=\mathrm{T}_{0}$ is on external border of the channel;

$T(0.0)=T_{0}(1-\varsigma)\left(c_{M} / c_{c}\right)+T_{y} \zeta\left(c_{y} / c_{c}\right)$ is on an input in the channel.where $\mathrm{z}$ is a share of hard phase of carbon dioxide in a mix with extruded material; $\mathrm{c}_{\mathrm{M}}, \mathrm{c}_{\mathrm{y}}, \mathrm{c}_{\mathrm{c}}$ are the thermal capacities of a material, carbon dioxide and a mix, $\mathrm{J} / \mathrm{kg} \cdot \mathrm{K}$.

The algorithm based on spectral methods of Galerckina, according to Fletcher (1988), is developed for a solution of the given problem. Product of functions from coordinate $\mathrm{z}$ and coordinate y enables to solve a problem stage by stage. Have as a result received initial approximation of a temperature structure:

$$
\begin{aligned}
T_{0}(y) & =T_{0}(1-\varsigma)+T_{y} \varsigma \\
& +\sum_{i=0}^{2}\left[A_{0_{i}}\left[\left(\frac{y-0,005}{0,005}\right)^{2 i+2}\right]\right] .
\end{aligned}
$$

Using numerical values of a vector of time projections $A_{i}$ (0) during the initial moment of time from the matrix equation, we make system of the ordinary differential equations 
corresponding the matrix equation:

$$
\frac{d}{d z}\left[a_{i}(z)\right]=[M]^{-1} m_{1}[D M]-m_{2}\left[a_{i}(z)\right]-m_{3}[M]^{-1}[Q] .
$$

The received system of the differential equations solved a method of Euler concerning a vector of derivatives $\frac{d}{d z}\left[a_{i}(Z)\right]$, using as initial values of a Cauchy problem, a vector $\mathrm{a}_{i}(0)$. The received dependence $\mathrm{a}_{i}(\mathrm{z})$ is used for definition of time projections of a solution of a boundary value problem that allows to receive approached a solution in the form of:

$$
\begin{aligned}
T(y, i) & =T_{0}(1-\varsigma)+T_{y} \cdot \varsigma+Z_{1_{i}}\left(\frac{y-0.005}{0.005}\right)^{2} \\
& +Z_{2_{i}}\left(\frac{y-0.005}{0.005}\right)^{4}+Z_{3_{i}}\left(\frac{y-0.005}{0.005}\right)^{6} .
\end{aligned}
$$

Decrease in average temperature on an initial site of the channel that is connected with an operation of a drain of heat at phase transition of solid $\mathrm{CO}_{2}$ is characteristic, and then increase in average temperature, basically due to selection of heat, is marked at friction of a material. Thus, defining influence of factor $m_{1}$ is established:

$$
m_{1}=\frac{\lambda_{M}}{\rho \cdot c_{p}} \frac{\left(H_{0} / H_{z}\right)^{2}}{w(y, z)} .
$$

So, influence of thermophysical properties of a material (factor of heat conductivity), a degree of compression of a material in the screw channel and speed of current of a material in the screw channel.

Calculations have been made for various length of the screw channel $\left(\mathrm{L}_{\mathrm{e}}=0.5 ; 0.75\right.$; и $\left.1.0 \mathrm{~m}\right)$. Representing the received factors functions from length of the screw channel also establish the common equation of a kind:

$$
\begin{aligned}
= & 0,233 \cdot L_{e}-0.143 \cdot L_{e}^{2}-0.102+T_{\mathrm{H} 34}-T_{\mathrm{KOH}} \\
= & +\left(8,549 \times 10^{5} \cdot L_{e}-3,429 \times 10^{5} \cdot L_{e}^{2}-4,049 \times 10^{5}\right) m_{1} \\
& +\left(6,064 \times 10^{11} \cdot L_{e}^{2}-1,119 \times 10^{12} \cdot L_{e}+5,007 \times 10^{11}\right) m_{1}^{2} .
\end{aligned}
$$

The amount of mixed solid-phase carbon dioxide to the supplied coriander seeds reached up to $5 \%$ in the composition of the mixture fed to the extruder. It is noted that this amount is sufficient to ensure that the temperature does not exceed $25-35^{\circ} \mathrm{C}$. However, a larger amount of solid-phase carbon dioxide did not have time to melt and this led to insufficiently expanded and moistened granules. When the content of solidphase carbon dioxide is $2-3 \%$ and the number of revolutions of the extruder is up to $140 \mathrm{rpm}$, the material at the exit from the matrix hole is expanded in the form of a loose material with "exploded" small particles. Temperature difference from equation (13) was obtained as $7.5^{\circ} \mathrm{C}$, which complies with experimental value of $8.5^{\circ} \mathrm{C}$ measured by thermocouple.

\subsection{Deformation of oil crops during extrusion process}

Extrusion process proceeding in the working channel with a varying pressure upon a processed material. The greatest pressure in a material is created at passage of an outlet of a matrix. The material at the matrix outlet is exposed to sharp (explosive) discharge of pressure. All these changes of pressure cause deformation of a material which properties finally depend on this process, especially from the last stage on its exit from matrix outlet.

The problem definition can be reduced to an axially symmetric task by considering the deformation of extruded material directly on an output from an outlet of a matrix (radial $\mathrm{u}$ and axial $\mathrm{w}$ movements without torsion). Thus here, the applicability of the elasticity theory (i.e., considering process parameters as effectiveness) and presentation of the scientific task in cylindrical coordinates is supposed.

$$
\begin{gathered}
\mu \nabla^{2} u+3(\lambda+\mu) \frac{\partial_{\mathrm{cp}}}{\partial r}-\frac{\mu}{r^{2}} u+3 \frac{\partial \lambda}{\partial r} \mathrm{cp}+2 \frac{\partial \mu}{\partial r} \frac{\partial u}{\partial r} \\
+\frac{\partial \mu}{\partial z}\left(\frac{\partial w}{\partial r}+\frac{\partial u}{\partial z}\right)-3 \frac{\partial}{\partial r}\left(K_{E}\right)=0 \\
\mu \nabla^{2} w+3(\lambda+\mu) \frac{\partial_{\mathrm{cp}}}{\partial z}+3 \frac{\partial \lambda}{\partial z} \mathrm{cp}+\frac{\partial \mu}{\partial r}\left(\frac{\partial u}{\partial z}+\frac{\partial w}{\partial r}\right) \\
+2 \frac{\partial \mu}{\partial z} \frac{\partial w}{\partial z}-3 \frac{\partial}{\partial z}\left(K_{E}\right)=0
\end{gathered}
$$

where

$$
{ }_{\mathrm{cp}}=\frac{1}{3}\left(\frac{\partial u}{\partial r}+\frac{u}{r}+\frac{\partial w}{\partial z}\right) ; \nabla^{2}=\frac{\partial^{2}}{\partial r^{2}}+\frac{1}{r} \frac{\partial}{\partial r}+\frac{\partial^{2}}{\partial z^{2}}
$$

Here, $\lambda$ and $\mu$ are the constants of Lyme and $K$ is the module of volumetric compression, expressed through where $\mathrm{E}$ is the module of elasticity (module of Young), $\mathrm{n}$ is the Poisson factor, and $\mathrm{G}$ is the module of shift.

$$
\begin{aligned}
\lambda & =\frac{E v}{(1+v)(1-2 v)} ; \mu=G=\frac{E}{2(1+v)} ; K \\
& =\frac{E}{3(1-2 v)} .
\end{aligned}
$$

The compelled deformation $\mathrm{e}_{\mathrm{B}}$ arising under an operation of developed pressure is subjected to present dependences for moving axial $E=\int_{P_{z}}^{0} \alpha_{P} d P$ and radial $E=\int_{P_{r}}^{0} \alpha_{P} d P$ with factor of linear expansion $a_{p}$.

If we assume that radial and axial movement depends on radial and axial coordinate accordingly, the equations (14) and (15) can be written as follows:

$$
\begin{gathered}
\frac{\partial^{2}}{\partial r^{2}}+\frac{1}{r} \frac{\partial u}{\partial r}-\frac{(1-2 v) u}{2(1-v) r^{2}}-\frac{(1+v) \alpha_{P} P_{0}}{(1-v) u\left(r_{0}\right)}=0, \\
\frac{2(1-v) \partial^{2} w}{(1-2 v) \partial z^{2}}-\frac{2(1+v) \alpha_{P} P_{0}}{(1-2 v) W_{L}}=0 .
\end{gathered}
$$

The equation (17) is the ordinary non-uniform differential equation of the second order and its solution describing radial expansion as follows: 


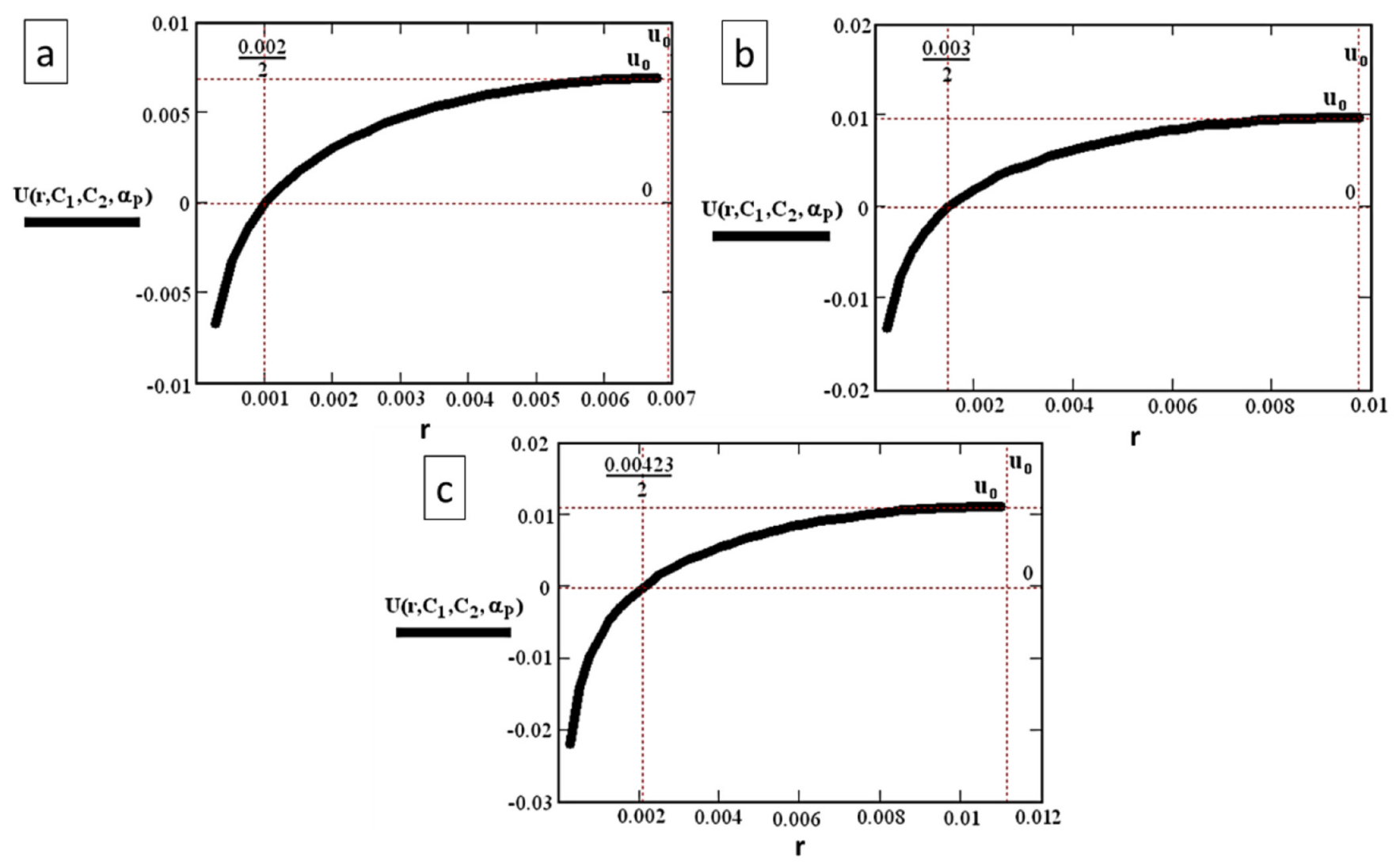

Fig. 4. The dependence of radial expansion for the case of matrix outlet diameter: (a) $d=2 \mathrm{~mm}$; (b) $d=3 \mathrm{~mm}$; (c) $d=4.23 \mathrm{~mm}$.

$$
u\left(r, C_{1}, C_{2}\right)=\left(C_{1} r^{\sqrt{b}}+C_{2} r^{-\sqrt{b}}\right)+\frac{D}{b-4} r^{2}
$$

where $D=\frac{(1+v) \alpha_{P} P_{0}}{(1-v) u\left(r_{0}\right)}$ and $b=\frac{1-2 v}{2(1-v)}$.

The equation (18) is the ordinary differential equation of the second order with divided variables and its solution, describing axial expansion, looks as follows:

$$
w\left(z, C_{1}, C_{2}, \alpha_{P}\right)=-\frac{1}{2} A Z^{2}+C_{1} z+C_{2},
$$

where $A=\frac{(1+v) \alpha_{P} P_{0}}{(1-v) W_{L}}$.

Constants of integration $\mathrm{C}_{1}$ and $\mathrm{C}_{2}$ in the equations (20) and (21) were found at boundary conditions:

$$
\begin{array}{r}
u\left(r_{0}, C_{1}, C_{2}\right)=0 \partial u\left(u\left(r_{0}\right), C_{1}, C_{2} / \partial r\right), \\
w\left(z=0, C_{1}, C_{2}\right)=0 \partial w\left(z=W_{L}, C_{1}, C_{2} / \partial z\right) .
\end{array}
$$

\subsection{Data assessment}

For identification of parameter $\alpha_{\mathrm{p}}$, experimental data for a coriander seeds were used (Meretukov and Koshevoy, 2014). The Poisson ratio was assumed to be equal to: $v=0.3-0.4$, which corresponds to properties of dispersed plant materials. The obtained results are shown below in Figures 4 and 5.
The Figure 4 shows that in specified sequence of preparation methods, the extractability (yield) of extractive substances mass increases. The Poisson factor was accepted as equal to: $n=0.3-0.4$, that corresponds to properties of disperse oil crops. Thus, experimental data comply with the model.

The analysis of variability confirms that difference of Poisson factor influence $\left(\mathrm{F}=0.493<\mathrm{F}_{\mathrm{cr}}=5.192\right)$, and influence of geometry of matrix outlet for axial and radial expansion $\left(\mathrm{F}=3.267<\mathrm{F}_{\mathrm{cr}}=5.318\right)$ on factor of linear expansion is statistically negligible.

The value of linear expansion factor for various modes of extrusion process remains constant. For $n=0.3$ and $n=0.4$, the average value of $\alpha_{P}=2.87 \pm 0.42 \mathrm{MPa}^{-1}$ and $\alpha_{\mathrm{P}}=2.61 \pm 0.43$ $\mathrm{MPa}^{-1}$, respectively. At the same time, the corresponding factor of volumetric expansion were $\alpha_{p v}=0.0236 \pm 0.012$ $\operatorname{bar}^{-1}$ and $\alpha_{p v}=0.0178 \pm 0.0103$ bar $^{-1}$.

\section{Conclusion}

A theoretical prospect of obtaining porous granules from oil crops by extrusion process technology has been presented in the present paper. The present research briefly described the process of extrusion and the principles of extruders operation as useful aspects of grain crops processing. This introduction was followed by modeling of compressibility statics of oil crops mixed with carbon dioxide. Next, we considered the issue of heat exchange and phase transformation during moving of oil crops with $\mathrm{CO}_{2}$ along the extruder channel. 

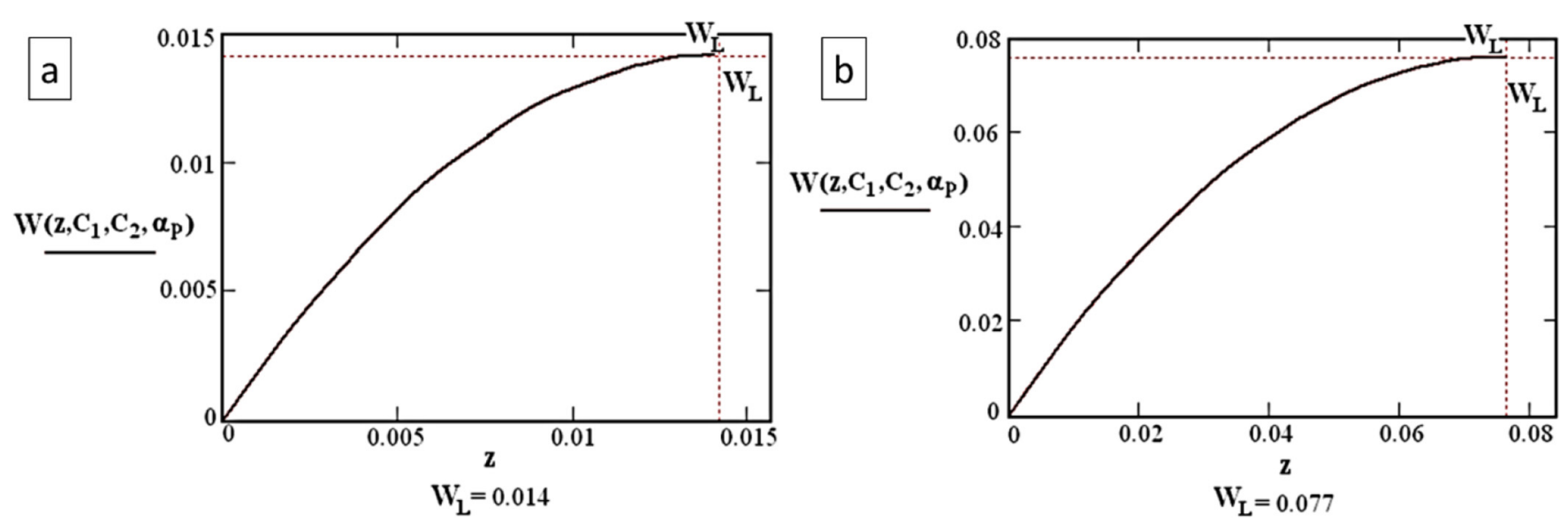

Fig. 5. The dependence of axial expansion for case of the matrix outlet length: (a) $\mathrm{L}=10 \mathrm{~mm}$; (b) $\mathrm{L}=50 \mathrm{~mm}$.

The deformation of oil crops during extrusion process has also been thoroughly examined.

The equation of Van der Waals was used for theoretical description of volumetric change of oil crops during the extrusion process when oil crops were mixed with carbon dioxide in solid phase, and its associated changes in pressure and temperature, the range of factors of expansion as determined by these (above-mentioned) equations - all those calculations proved that grain crop can eventually expand especially at the outlet of extruder matrix. The complex nature of these data, especially in terms of compressibility, density, and factors related with the volumetric expansion and deformation of oil crops mixed with carbon dioxide in solid phase, retain their importance within the varying ranges of pressure and temperatures.

For theoretical prospects, it will be feasible and useful to consider the factors that determine the development and functionality of extrusion process technology. The theoretical prospect of environmentally friendly method of extrusion processing can serve as an example of how environmentally friendly method relates to its productivity (whether it includes continuous, flexible, various aspects of extrusion processing), peculiar for processing of the oilseed crops, for example. Perhaps, this theoretical prospect will contribute to better theoretical understanding the extrusion processing parameters before deformation of oilseeds, which will help to supplement the information available in this subject area. Obtained results of porous granules formation from oil crops mixture with hard phase carbon dioxide can be used as an effective food processing technology.

\section{Nomenclature}

$\mathrm{P}$
$v$
$\pi, \omega$ and $\mathrm{R}^{\prime}$
$\alpha_{p v}$
$\rho$
$\mathrm{A}_{\text {compr }}$

Pressure, bar

Specific volume, $\mathrm{m}^{3} / \mathrm{kg}$

Empirical constants

Factor of volumetric expansion

Density, $\mathrm{kg} / \mathrm{m}^{3}$

Compression value
$\mathrm{C}$

$w=w(y, z)$

$l$

$\mathrm{S}$

$H_{z}=\left(H_{0}-a z\right)$

$H_{0}$

$\mathrm{m}$

$L_{e}$

$S_{c}$

$\mathrm{q}=\operatorname{arctg}\left[\mathrm{S} /\left(\mathrm{pD}_{\mathrm{e}}\right)\right]$

$f_{d}=1-\left(0.487 n^{2}\right.$

$-0.948 n+0.972) H_{z} / W$

$f_{p s}=1-\left(0.949 n^{2}-1.87 n\right.$

$\left.\stackrel{f_{p s}}{+} 1.59\right) H_{z} / W$

$f_{p d}=0.98$

$\mathrm{D}_{\mathrm{e}}$

N

$\mathrm{n}$

Z

Indexes

c Mixture

y Carbon dioxide

m Material
Specific thermal capacity, $\mathrm{J} / \mathrm{K} \cdot \mathrm{kg}$ Distribution of speed of extruded material in relation to coordinates $\mathrm{y}$ and $\mathrm{z}, \mathrm{m} / \mathrm{s} ; T=T(y, z)$ distribution of temperature of extruded material on coordinates $\mathrm{y}$ and $\mathrm{z}, \mathrm{K}$ Heat conductivity, $\mathrm{Wt} / \mathrm{m} \cdot \mathrm{K}$

Drain of heat at phase transition of carbon dioxide, $\mathrm{Wt} / \mathrm{m}^{2}$

Variable depth of the channel, $m$ Initial depth of a coil, $\mathrm{m}$

Viscosity, $\mathrm{Pa} \cdot \mathrm{s}$

Length of the channel, $m$

Screw turn step, $\mathrm{m}$

Angle of inclination of coil thread, radian

Factor of form of forced stream

Factor of form for a countercurrent caused by resistance of the target device

Correcting factor for average viscosity in stream (for the area of interest)

Diameter of the case of extruder, $m$ Screw extruder rotation speed, $\mathrm{s}^{-1}$ Parameter of the sedate law in the equation of current of extruded material (non-Newtonian liquid: for oil crops $n=0.13$ )

A share of hard phase of carbon dioxide in a mix with extruded material 
Acknowledgments. The research was carried out using the equipment of the Research Center for Food and Chemical Technologies of KubSTU (CKP_3111).

\section{References}

Alam MS, Kaur J, Khaira H, Gupta K. 2016. Extrusion and extruded products: Changes in quality attributes as affected by extrusion process parameters: A review. Crit Rev Food Sci Nutr 56(3): 445-473.

Bernhard EC. 1974. Processing of thermoplastic materials. In: Plastic Engineering Series. New York, USA: Krieger Publishing Company, ISBN: 9780882751450.

Bisharat GI, Oikonomopoulou VP, Panagiotou NM, Krokida MK, Maroulis ZB. 2013. Effect of extrusion conditions on the structural properties of corn extrudates enriched with dehydrated vegetables. Food Res Int 53(1): 1-14.

Bouvier J-M, Campanella OH. 2014. Extrusion processing technology: Food and non-food biomaterials. West Sussex, UK: John Wiley \& Sons Ltd., pp. 536, ISBN: 978-1-4443-3811-9.

Chiruvella RV, Jaluria Y, Karwe MV. 1996. Numerical simulation of the extrusion process for food materials in a single-screw extruder. J Food Eng 30: 449-467.

De Melo MMR, Sen A, Silvestre AJ, Pereira H, Silva CM. 2017. Experimental and modeling study of supercritical $\mathrm{CO}_{2}$ extraction of Quercus cerris cork: Influence of ethanol and particle size on extraction kinetics and selectivity to friedelin. Separat Purificat Technol 187: 34-45.

del Valle JM. 2015. Extraction of natural compounds using supercritical $\mathrm{CO}_{2}$ : Going from the laboratory to the industrial application. J Supercrit Fluids 96: 180-199.

del Valle JM, de la Fuente JC. 2006. Supercritical $\mathrm{CO}_{2}$ extraction of oilseeds: Review of kinetic and equilibrium models. Crit Rev Food Sci Nutr 46(2): 131-160. https://doi.org/10.1080/ 10408390500526514.

Fletcher K. 1988. Numerical methods on the basis of Galerckina. World, Moscow (in Russian).

Isobe S, Zuber F, Uemura K, Noguchi A. 1992. A new twin-screw press design for oil extraction of dehulled sunflower seeds. $\mathrm{J} \mathrm{Am}$ Oil Chem Soc 69(9): 884-889.

Jedinger N, Schrank S, Mohr S, Feichtinger A, Khinast J, Roblegg E. 2015. Alcohol dose dumping: The influence of ethanol on hotmelt extruded pellets comprising solid lipids. Eur J Pharm Biopharm 92: 83-95.

Maskan M, Altan A. 2012. Advances in food extrusion technology. Florida, USA: CRC Taylor \& Francis Group, pp. 398, ISBN: 978-1-4398-1521-2.
Meretukov ZA, Koshevoy EP. 2014. Increase of efficiency of process of extraction of oil from vegetative raw material with application of dioxide of carbon. In: 21st International Congress of Chemical and Process Engineering, CHISA 2014 and 17th Conference on Process Integration, Modelling and Optimisation for Energy Saving and Pollution Reduction, PRES 2014, pp. 445-445.

Núñez GA, Gelmi CA, del Valle JM. 2011. Simulation of a supercritical carbon dioxide extraction plant with three extraction vessels. Comput Chem Eng 35: 2687-2695. https://doi.org/ 10.1016/j.compchemeng.2011.04.002.

Núñez GA, del Valle JM, Navia D. 2017. Supercritical $\mathrm{CO}_{2}$ oilseed extraction in multi-vessel plants. 3. Effect of extraction pressure and plant size on production cost. J Supercrit Fluids 122: 109-118. https://doi.org/10.1016/j.supflu.2016.11.002.

Riaz MN, ed. 2000. Extruders in food applications. Florida, USA: CRC Taylor \& Francis Group, pp. 242, ISBN: 978-1-56676-779-8.

Said AB, Guinot C, Ruiz JC, et al. 2016. Supercritical $\mathrm{CO}_{2}$ extraction of contaminants from polypropylene intended for food contact: Effects of contaminant molecular structure and processing parameters. J Supercrit Fluids 110: 22-31.

Shihani N, Kumbhar BK, Kulshrshtha M. 2006. Modeling of extrusion process using response surface methodology and artificial neural networks. J Eng Sci Technol 1(1): 31-40.

Singh S, Gamlath S, Wakeling L. 2007. Nutritional aspects of food extrusion: A review. Int J Food Sci Technol 42: 916-929.

Song Y, Zheng L, Zhang X. 2017. Kinetics model for supercritical fluid extraction with variable mass transport. Int $J$ Heat Mass Transf 112: 876-881.

Sriti J, Talou T, Faye M, Vilarem G, Marzouk B. 2011. Oil extraction from coriander fruits by extrusion and comparison with solvent extraction processes. Ind Crops Prod 33: 659-664.

Toledo FR, del Valle JM, Opazo ÁP, Núnez GA. 2020. Supercritical $\mathrm{CO}_{2}$ extraction of pelletized oil seeds. Representation using a linear driving force model with a nonlinear sorption isotherm. J Food Eng 288: 110241.

Tong H, Hai J. 2017. Extraction of garlic essential oil from a slurry by random packing combined with supercritical fluid technology. $J$ Comput Theor Nanosci 14(9): 4597-4602.

Uitterhaegen E, Evon P. 2017. Twin-screw extrusion technology for vegetable oil extraction: A review. J Food Eng 212: 190-200.

Urrego FA, Núñez GA, Donaire YD, del Valle JM. 2015. Equilibrium partition of rapeseed oil between supercritical $\mathrm{CO}_{2}$ and prepressed rapeseed. J Supercrit Fluids 102: 80-91. https://doi.org/10.1016/j. supflu.2015.04.004.

Vandenbossche V, Candy L, Evon P, Rouilly A, Pontalier P-Y. 2019. Extrusion. Green Food Process Tech, 289-314. https://doi.org/ 10.1016/b978-0-12-815353-6.00010-0.

Cite this article as: Meretukov ZA, Koshevoy EP, Shorstkii IA, Okpala COR. 2021. Porous granules formation from oil crops by extrusion process: a theoretical perspective. OCL 28: 47. 